\title{
Anti-estrogen-resistant breast cancer cells are sensitive to cisplatin plus TRAIL treatment
}

\author{
SHUPING YIN ${ }^{1}$, ARUN K. RISHI ${ }^{2}$ and KALADHAR B. REDDY ${ }^{1,2}$ \\ ${ }^{1}$ Department of Pathology, Wayne State University School of Medicine; ${ }^{2}$ Department of Oncology, \\ Karmanos Cancer Institute, Wayne State University, Detroit, MI 48201, USA
}

Received November 7, 2014; Accepted December 9, 2014

DOI: 10.3892/or.2015.3721

\begin{abstract}
Breast cancer patients who are positive for estrogen receptor (ER) are usually treated with anti-estrogen drugs, such as tamoxifen (Tam). However, a great majority of such patients eventually develop resistance to Tam. In this study, MCF-7 cells (with de novo and/or acquired resistance to Tam) as well as T47D cells (acquired resistance to Tam) models were used to investigate the effect of treatment with cisplatin plus tumor necrosis factor-related apoptosis-inducing ligand (TRAIL). The results in the two cell types treated with cisplatin plus TRAIL showed significantly increased cell death compared to that in the untreated control cells. A similar treatment had a minimal effect on normal breast cells, the increased cell death appeared to be caused by the activation of caspases and, inhibition of the activity of caspases (using relatively specific inhibitors) reduced the cell death caused by cisplatin plus TRAIL treatment. Taken together, the results suggested that cisplatin plus TRAIL treatment has the potential to provide a novel treatment strategy to improve the treatment outcome in anti-estrogen-resistant breast cancer patients.
\end{abstract}

\section{Introduction}

Hormonal influence on breast tissue and in breast cancer development has long been recognized. Examinations of $\sim 70 \%$ of breast cancer patients have been found to be positive for estrogen receptor (ER)/progesterone (PR) receptor $(1,2)$. Additionally, the receptor status has been used as a biomarker

Correspondence to: Dr Kaladhar B. Reddy, Department of Pathology, Wayne State University, 540 E. Canfield Avenue, Detroit, MI 48201, USA

E-mail: kreddy@med.wayne.edu

Abbreviations: TRAIL, tumor necrosis factor-related apoptosisinducing ligand; PARP, poly(ADP-ribose) polymerase; ER, estrogen receptor; HER2, human epidermal growth factor receptor 2; Tam, tamoxifen

Key words: anti-estrogen resistance, breast cancer, cisplatin, TRAIL, apoptosis, cell death for therapy and prognosis. Currently, ER/PR ${ }^{+}$breast cancer patients are treated with anti-estrogen drugs, such as tamoxifen (Tam) or aromatase inhibitors (AIs) $(3,4)$. Tam binds to ER, thereby preventing the binding of estrogen and subsequent activation of ER. Aromatase inhibitors (AI) suppress the activity of aromatase enzyme and thus, the production of estrogen. Although these inhibitors were shown to be effective, some patients develop resistance and do not respond to Tam therapy or other targeted endocrine therapies. The de novo resistance appears to be due to the up-regulation/overexpression of the HER2 receptor and/or Akt protein. Clinical and in vitro studies have also suggested that overexpression of the HER 2 receptor is associated with resistance to hormone therapy (5-7). In addition, the majority of breast cancer patients with ER expression initially respond to endocrine therapy but, develop 'acquired' resistance over a period of time (8). MCF-7 and T47D breast cancer cell lines have been used as experimental models to investigate the mechanism(s) involved in acquired resistance to Tam $(5,9,10)$. The results from such studies reported by our and other research groups have shown that drug resistance in these cells can be acquired through various mechanisms, including: i) loss of ER $\alpha$ expression, ii) altered activity of co-regulators, iii) cross-talk between the ER $\alpha$ and growth factor signaling pathways and, iv) overexpression of PKC $\alpha$ or PKC $8(3,5,11)$. These anti-estrogen-resistant models are also useful for the identification of other 'potential' therapeutic agents that can inhibit or eliminate anti-estrogen-resistant breast tumors.

Tumor necrosis factor-related apoptosis-inducing ligand (TRAIL) induced apoptosis through the death receptors, DR4 and DR5, which are present at the surface of target cells $(12,13)$. Recombinant human TRAIL was shown to induce apoptosis preferentially in cancer over normal cells, and appear to have little or no overt toxicity when systemically administered to animals $(12,14)$. Consequently, numerous clinical trials targeting TRAIL receptors, including TRAIL, as well as agonistic antibodies to DR4 and DR5 have been conducted. However, a significant portion of tumor cells, including breast cancer cells, were reported to be resistant to these agents $(13,15-17)$. In this context, the use of platinum complexes for breast cancer therapy has emerged as a new treatment modality. Cisplatin, either independently or in combination with other chemotherapeutic drugs, was shown to be effective in the treatment of breast cancer $(18,19)$. Cisplatin induces intra- and inter-strand cross-links in DNA leading to 
cell death. The aim of the present study was to investigate whether cisplatin plus TRAIL treatment induced cell death and apoptosis in Tam-resistant cells and whether such a combinatorial treatment provides a new strategy for future therapeutic intervention of patients with anti-estrogen-resistant breast cancer.

\section{Materials and methods}

Cell lines and reagents. The MCF-7 human breast carcinoma cell line was obtained from the American Type Culture Collection (ATCC; Manassas, VA, USA) and maintained in Dulbecco's modified Eagle's medium (DMEM), supplemented with 5\% FCS and insulin, and penicillin and streptomycin (Life Technologies, Gaithersburg, MD, USA). Stably transfected MCF-7 cells with full-length HER2 cDNA (MCF-7/HER2-18) or control vector (MCF-7/neo) have been previously described (9). Tam/MCF-7 cells were grown in the presence of 4-OH Tam $\left(10^{-6} \mathrm{M}\right)(20)$. The cells obtained from ATCC were immediately expanded and frozen, and restarted every 3-4 months from a frozen vial of the same batch of cells and no additional authentication was done on these cells. 4-OH Tam was purchased from Sigma Chemical Co. (St. Louis, MO, USA). The anti-glyceraldehyde-3-phosphate dehydrogenase (G3PDH) rabbit polyclonal was purchased from Trevigen (Gaithersburg, MD, USA). Monoclonal antibodies of PARP and Bid were purchased from BD Biosciences (San Diego, CA, USA). Caspase-9 antibodies were purchased from Cell Signaling Technology, Inc. (Boston, MA, USA). Caspase-3 inhibitor Z-DEVD-FMK, Caspase-8 inhibitor Z-IETD-FMK, Caspase-9 inhibitor Z-LEHD-FMK, and pancaspase inhibitor Z-VAD-FMK were purchased from R\&D System (Minneapolis, MN, USA). Unless otherwise specified, any other chemicals were obtained from Sigma Chemical Co. at highest suitable purities.

MTT assay. Briefly, $5 \times 10^{4}$ cells were added in 96-well tissue culture plates. After $24 \mathrm{~h}$, the cells were treated with TRAIL $(10 \mathrm{ng} / \mathrm{ml})$, cisplatin $(10 \mu \mathrm{g} / \mathrm{ml})$, or a combination of TRAIL plus cisplatin for another 24 or $48 \mathrm{~h}$. Then, $100 \mu \mathrm{l}$ of 3-(4,5-dimethylthiazol-2-yl)-2,5-diphenyltetrazolium bromide (MTT) $(1 \mathrm{mg} / \mathrm{ml})$ was added into each sample and incubated for $3 \mathrm{~h}$ under $5 \% \mathrm{CO}_{2}$ and $37^{\circ} \mathrm{C}$. The cell viability was measured by MTT, which was converted by succinate dehydrogenase in the mitochondria of viable cells to yield a purple formazan dye. The formazan dye was dissolved in dimethyl sulfoxide (DMSO) and measured by absorption at a wavelength of $550 \mathrm{~nm}$ using Benchmark ${ }^{\circledR}$ microplate reader from Bio-Rad (Hercules, CA, USA).

Apoptosis assay. Apoptosis was assessed using the Cell Death Detection ELISAplus kit (Roche Applied Science, Indianapolis, IN, USA) according to the manufacturer's instructions. This kit quantitatively detects cytosolic histoneassociated DNA fragments. Briefly, the cells were treated with cisplatin $(10 \mu \mathrm{g} / \mathrm{ml})$ and TRAIL $(10 \mathrm{ng} / \mathrm{ml})$ or a combination of cisplatin $(10 \mu \mathrm{g} / \mathrm{ml})$ plus TRAIL $(10 \mathrm{ng} / \mathrm{ml})$ for $16 \mathrm{~h}$ of treatment. Apoptosis was quantified by ELISA and normalized to values measured in untreated cells. Data were presented as the mean \pm SEM of triplicate determination.
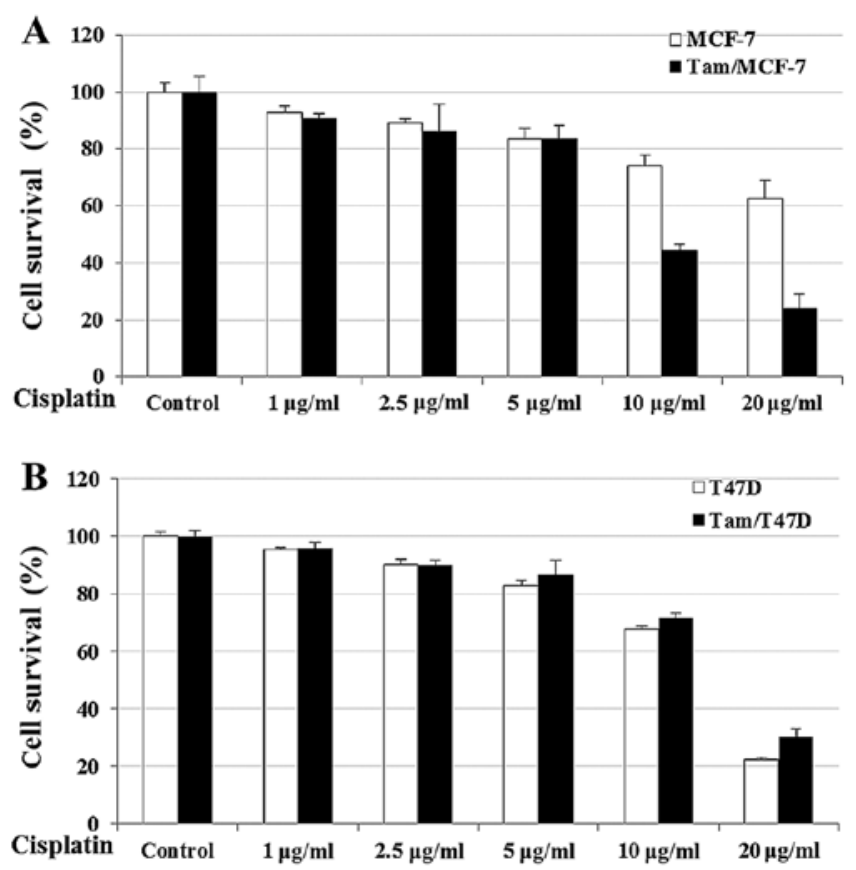

Figure 1. Effect of different concentrations of cisplatin on cell survival in anti-estrogen parental/sensitive and resistant MCF-7 and T47D breast cancer cell lines. Cells were treated with the indicated concentrations of cisplatin for $48 \mathrm{~h}$. Cell viability was then analyzed by MTT method. The results are expressed relative to the corresponding untreated controls. Data are the mean \pm SEM of triplicate determinants.

Western immunoblot analysis. The cells were grown in 6-well plates, to near confluence in the presence or absence of various treatments. The cells were lysed and western blotting was performed as previously described (5) using a standard protocol. Briefly, the cell extracts were obtained by lysing the cells in RIPA buffer $(20 \mathrm{mM}$ Hepes, $100 \mathrm{mM} \mathrm{NaCl}, 0.1 \%$ SDS, $1 \%$ Nonidet P-40, $1 \%$ deoxycholate, $1 \mathrm{mM} \mathrm{Na}_{3} \mathrm{VO}_{4}$, $1 \mathrm{mM}$ EGTA, $50 \mathrm{mM} \mathrm{NaF}, 10 \%$ glycerol, 1 mM EDTA, $1 \mathrm{mM}$ phenylmethylsulfonyl fluoride, and $1 \mathrm{X}$ protease inhibitor mixture). The samples containing $100 \mu \mathrm{g}$ of total protein were electrophoresed on $8 \%$ or $15 \%$ SDS-polyacrylamide gels and transferred on to PVDF membranes by electroblotting. The membranes were probed with antibodies as indicated, followed by HRP-conjugated mouse or rabbit secondary antibodies (Amersham Amersham Biosciences, Piscataway, NJ, USA). Anti-G3PDH was used for loading controls.

Statistical analysis. Data are presented as mean \pm SEM, and statistically analyzed using the unpaired Student's t-test. Differences were considered statistically significant when $\mathrm{P}<0.05$.

\section{Results}

Cisplatin plus TRAIL enhances cell death in anti-estrogenresistant and -sensitive cells without significantly effecting normal breast cells. To develop new strategies to eliminate anti-estrogen-resistant and -sensitive breast cells, we examined the effect of cisplatin on Tam/MCF-7 and Tam/T47D cells. Cell survival is shown in Fig. 1. Treatment of the cells with Cisplatin induced a significant decrease in cell survival in the 
A

Treatment time: 24 h

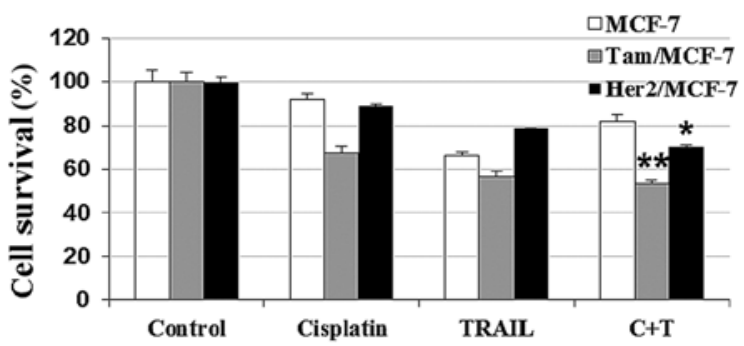

B

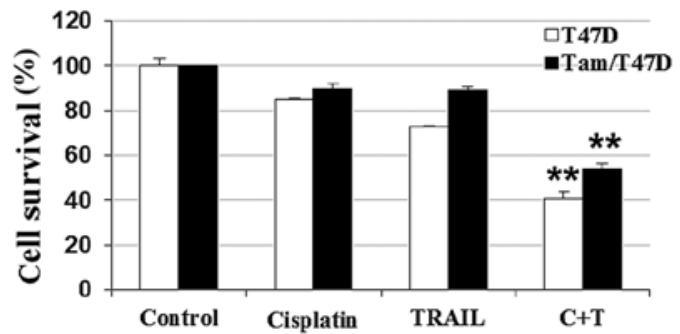

C

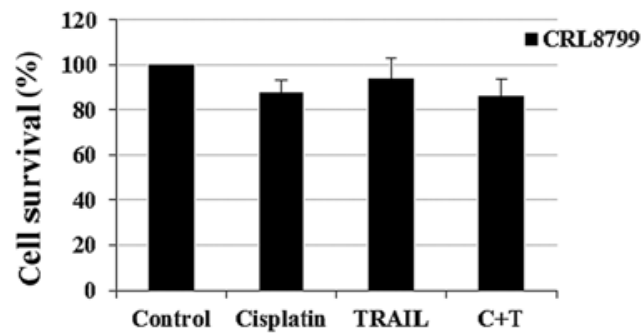

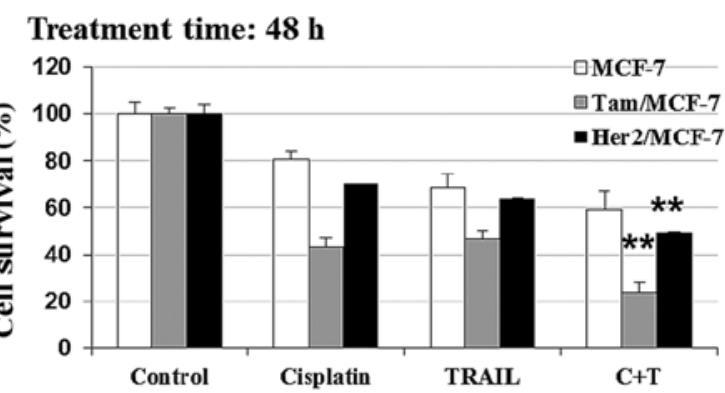
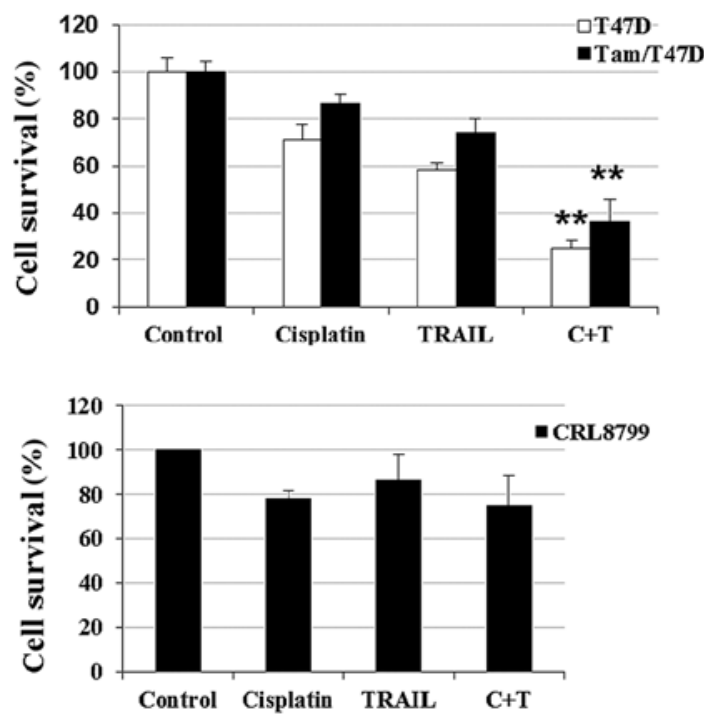

Figure 2. Cisplatin plus TRAIL treatment results in a significantly enhanced cell death in Tam/MCF-7, HER-2/MCF-7 and Tam T47D anti-estrogen-resistant cells without affecting CRL8799 normal breast cells. The cells were treated with cisplatin (C) $(10 \mu \mathrm{g} / \mathrm{ml})$, TRAIL (T) $(10 \mathrm{ng} / \mathrm{ml}) \mathrm{or} \mathrm{cisplatin}(10 \mu \mathrm{g} / \mathrm{ml})$ plus TRAIL (10 ng/ml) for 24 and $48 \mathrm{~h}$. Cell viability was then analyzed by an MTT assay. Cisplatin plus TRAIL (C+T) treatment significantly inhibited (A) Tam/MCF-7 ( $\mathrm{P}<0.05)$ and Her2/MCF-7 ( $\mathrm{P}<0.05)$ compared to untreated sensitive cells. (B) However, in T47D cells both sensitive and Tam/T47D cells were inhibited by cisplatin plus TRAIL treatment. (C) Similar treatment of CRL8799 normal breast cells resulted in a moderate increase in cell death. Data are the mean \pm SE of triplicate determinants $\left({ }^{* *} \mathrm{P}<0.01,{ }^{*} \mathrm{P}<0.05\right)$.

Tam/MCF-7 and Tam/T47D cells. The efficacy of cisplatin was dose-dependent; however, a significant risk of nephrotoxicity frequently hindered the use of higher doses to maximize the antitumor effects of cisplatin (21). Our data showed that $10 \mu \mathrm{g} / \mathrm{ml}$ of cisplatin exhibited optimum inhibition in MCF-7and T47D-derived anti-estrogen-resistant cells (Fig. 1). In addition, the results showed that cisplatin was more effective in killing anti-estrogen-resistant cells when compared to sensitive cells in the MCF-7 cell line. However, in the T47D-derived cell lines Tam-resistant and -sensitive cells were killed (Fig. 1). The reasons for this discrepancy in ER-positive breast cell lines remains to be determined.

We evaluated whether a combination of cisplatin plus TRAIL enhanced killing in anti-estrogen-resistant cells. Fig. 2 shows that cisplatin or TRAIL treatment decreased cell survival in Tam/MCF-7 (acquired resistance to Tam), HER2/MCF-7 (de novo resistance) and Tam/T47D (acquired resistance to Tam) cells to varying degrees. However, cisplatin plus TRAIL had a maximum effect on anti-estrogen-resistant cells by $48 \mathrm{~h}$. A similar treatment of CRL8799 normal breast cells resulted in a moderate increase in cell death.

Cisplatin plus TRAIL enhances apoptosis in Tam-resistantcells. Most chemotherapy agents and irradiation trigger apoptosis through the cell-intrinsic pathway, as an indirect consequence of cell damage. The intrinsic pathway usually requires functional p53. However, inactivation of p53, either directly through mutation(s) or indirectly through p53 modulation through the MDM2 protein, is common in many human tumors. The extrinsic pathway induces apoptosis in response to the engagement of death receptors by their ligands such as TRAIL. This pathway stimulates the apoptotic caspase mechanism independent of p53 (22). The effect of cisplatin, TRAIL, and cisplatin plus TRAIL treatment on apoptosis in Tam/MCF-7 and Tam/ T47D cells are shown in Fig. 3. Although treatment with cisplatin or TRAIL increased apoptosis to varying degrees, a combination of cisplatin plus TRAIL had a maximum effect on apoptosis in Tam/MCF-7 (Fig. 3A), and Tam/T47D (Fig. 3B) cells $(\mathrm{p}<0.05)$. These data suggested that cisplatin plus TRAIL increased apoptosis in anti-estrogen-resistant cells compared with the untreated controls.

Caspase inhibition reduces cisplatin plus TRAIL-induced cell death. Caspases have been previously shown to play an important role in TRAIL-induced apoptosis (23). It was previously shown that $75 \%$ of human breast tumors lack caspase- 3 transcripts, whereas other caspases, such as caspase- 8 and -9 were shown to be normal (24). MCF-7 cells lack caspase-3 expression as a 
A

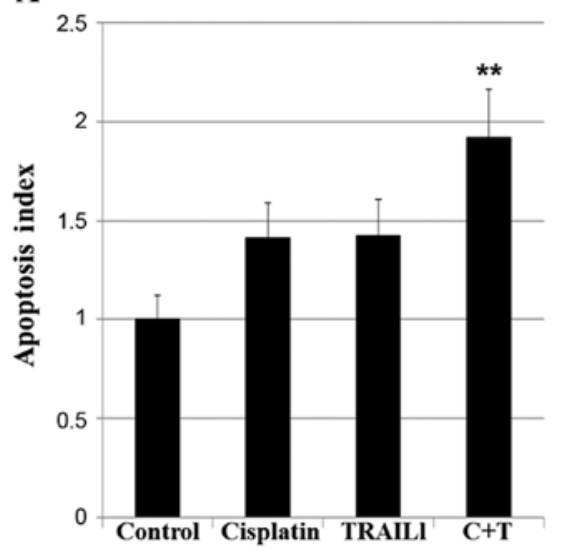

B

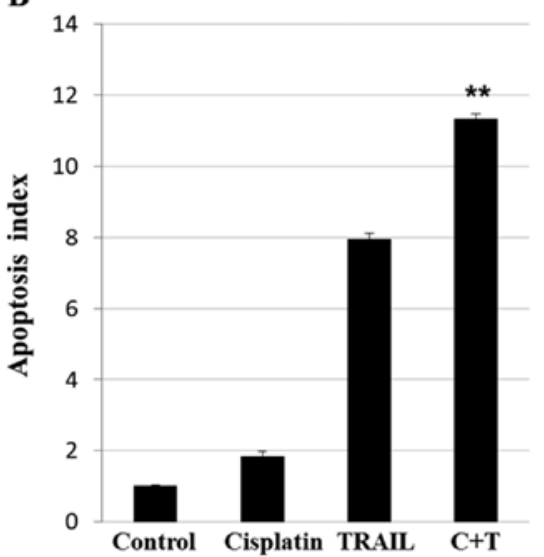

Figure 3. Cisplatin plus TRAIL increases apoptosis in anti-estrogen resistant cells. Apoptosis was quantified by Cell Death ELISA and normalized to values measured in untreated cells. Anti-estrogen-resistant cells showed a significant increase in apoptosis in the presence of cisplatin plus TRAIL in comparison to untreated cells in (A) MCF-7 and (B) T47D-derived Tam-resistant cells. Data are the mean \pm SEM of triplicate determinants.
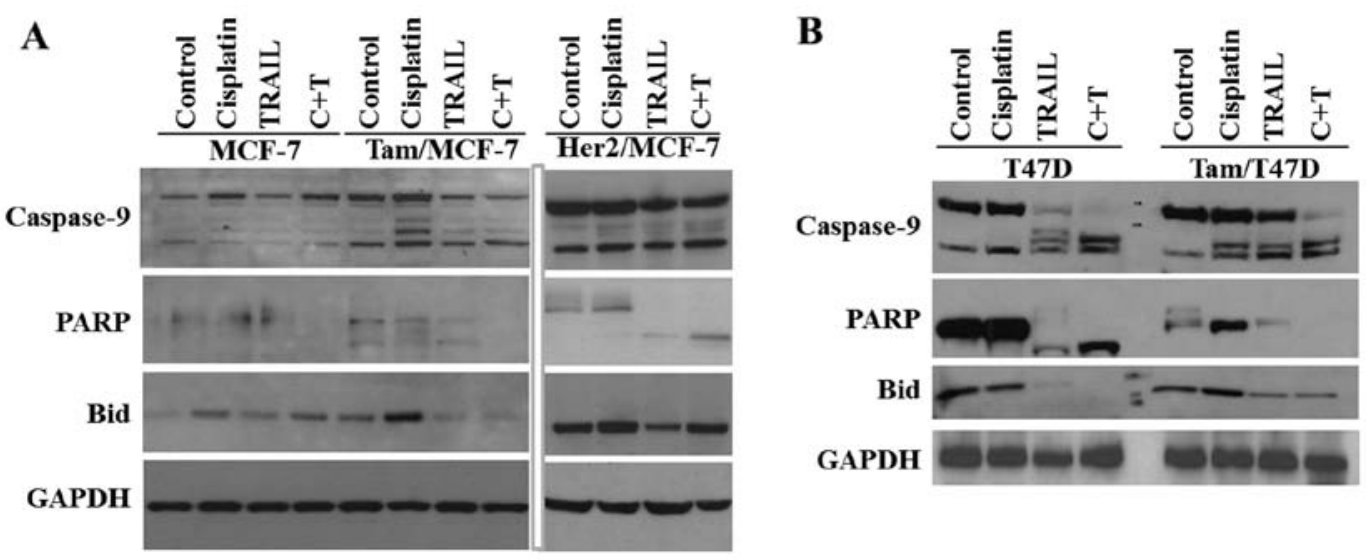

Figure 4. Cisplatin plus TRAIL treatment increases caspase activation in (A) in Tam/MCF-7 and Her-2/MCF-7 anti-estrogen-resistant cells and (B) T47D and Tam/T47D, leading to increased PARP and Bid cleavage. Cells were treated with cisplatin, TRAIL or cisplatin plus TRAIL for 24 h. The cells were harvested and a western blot analysis of caspase-9, PARP and Bid was performed. Equal protein loading was compared to that of GAPDH.

result of a functional deletion mutation in the caspase-3 gene, while the expression of other caspase- 8 and -9 remains normal. We used MCF-7 and T47D anti-estrogen cells to determine the possible mechanism by which cisplatin plus TRAIL increase cell death. The results from the western blot analyses revealed an increased caspase- 9 activation in Tam/MCF-7 and Her-2/MCF-7 anti-estrogen-resistant cells compared to -sensitive cells and this led to increased PARP and Bid cleavage (Fig. 4A) and apoptosis (Fig. 3A). By contrast, T47D and Tam/T47D (express caspase-3) showed a higher activation of caspase- 3 and -9 in resistant and sensitive cells in the presence of cisplatin plus TRAIL, leading to increased PARP and Bid cleavage (Fig. 4B).

To determine whether caspase activation is essential for cisplatin plus TRAIL-induced cell death, we blocked caspase-3, $-8,-9$ or pan-caspase using relatively specific caspase inhibitor(s). The effect of caspase inhibitors on cisplatin plus TRAIL treatment in Tam/MCF-7 HER2/MCF-7 and Tam/ T47D cells are shown in Fig. 5. However, the addition of caspase inhibitors alone to anti-estrogen-resistant cells had a minimal or no effect on these cells. These data suggested that cisplatin plus TRAIL-induced apoptosis is predominantly mediated through the activation of caspases in Tam-resistant cells.

\section{Discussion}

Anti-estrogenic drugs such as Tam provide an effective therapy for women with hormone-dependent breast cancer in the neo-adjuvant, adjuvant and advanced disease settings (25). However, a major clinical problem with the use of anti-estrogens is that the majority of patients with advanced disease eventually develop resistance to the compounds and even stimulate tumor growth in some cases $(26,27)$. Thus, Tam resistance is a daunting challenge for the successful treatment of ER-positive and hormone-dependent breast cancer. Preclinical and clinical investigations conducted to understand this resistance have led to the identification of multiple pathways that contribute to anti-estrogen resistance, most of which arise from alterations in $\mathrm{ER}^{-}$and/or growth factor receptor signaling (28).

In this study, instead of managing or preventing antiestrogen resistance, we attempted the strategy of eliminating endocrine-resistant cells by inducing enhanced cell death. The results from the present investigations have shown that Tam/MCF-7 and Tam/T47D cells, when treated with cisplatin plus TRAIL, exhibited significantly enhanced cell death as compared with the untreated cells. Furthermore, a similar 

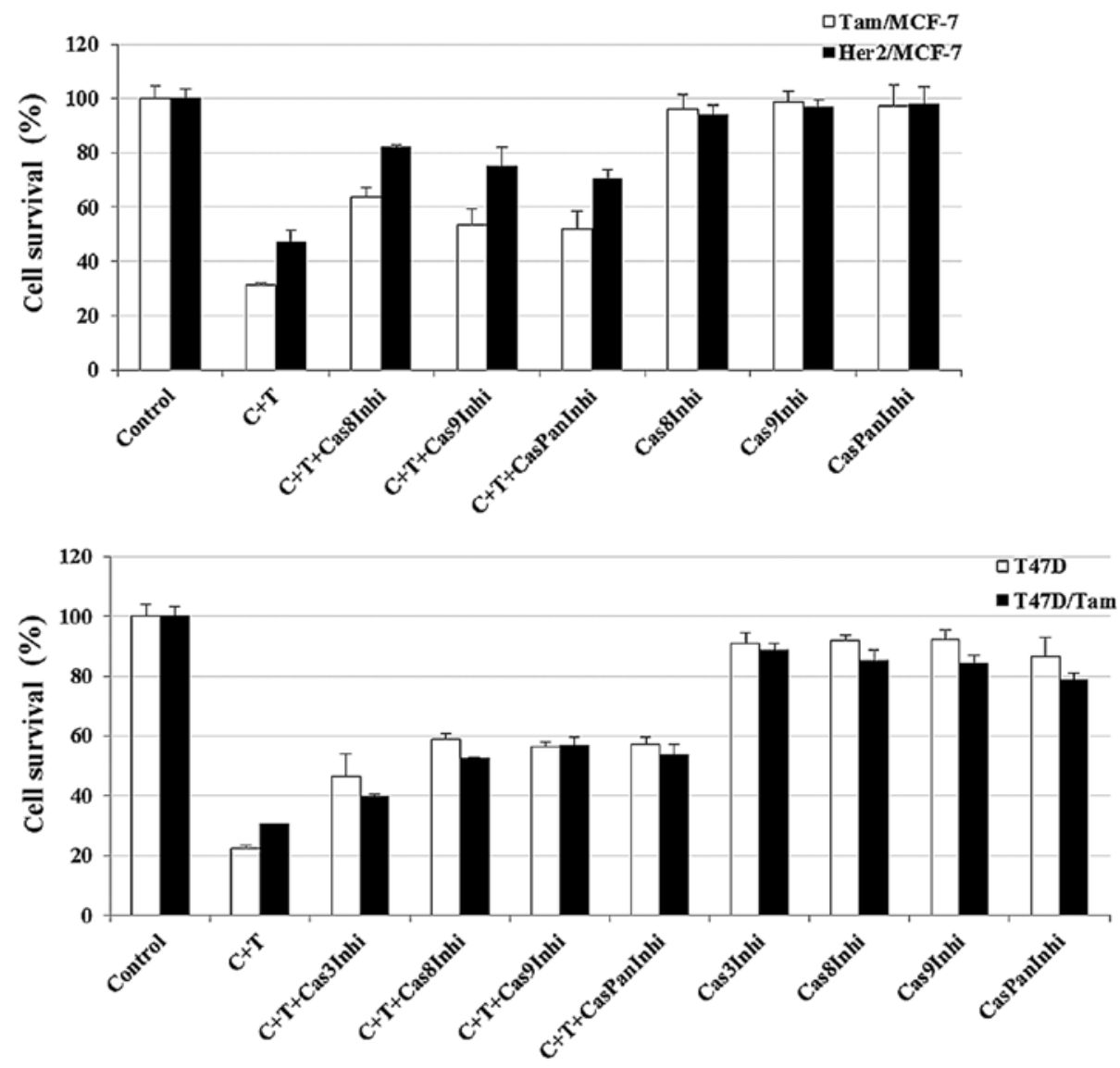

Figure 5. Caspase inhibition reduces cisplatin plus TRAIL cell death. The cells were treated for $48 \mathrm{~h}$ with cisplatin plus TRAIL and/or caspase inhibitors. Caspase inhibitors caspase-3 inhibitor Z-DEVD-FMK, caspase-8 inhibitor Z-IETD-FMK, caspase-9 inhibitor Z-LEHD-FMK, and pan-caspase inhibitor Z-VAD-FMK at a final concentration of $20 \mu \mathrm{M}$. Cell viability was then analyzed by MTT assay. The results are presented relative to the corresponding untreated controls. Data are the mean \pm SEM of triplicate determinants.

treatment had a minimal effect on CRL8799 normal breast cells. In addition, results from the present study provided evidence that cisplatin enhances TRAIL-induced cell death by activation of caspases. Inhibition of the activity of caspases decreased cell death in cisplatin alone and cisplatin plus TRAIL-treated cells.

The results also showed that cisplatin plus TRAIL significantly induces cell death in the de novo Tam-resistant (HER2/MCF-7) and acquired Tam-resistant (Tam/MCF-7) cells when compared to the MCF-7 parental cells. These observations were similar to those reported by Yde et al (29): MCF-7-derived anti-estrogen-resistant cells were more sensitive to cisplatin-induced cell death than the parental cells. The results from this study suggest that treatment with cisplatin or TRAIL alone induced cell death in $30-50 \%$ of Tam-resistant cells, however, the maximum effect is evident when these cells are treated with cisplatin plus TRAIL. There were differences in the response between Tam-resistant and parental T47D cells when compared to MCF-7 cells. Cisplatin plus TRAIL treatment significantly inhibited cell survival in Tam-T47D and T47D cells. However, the extent of cell death was different between Tam/MCF-7 and MCF-7 cells, the latter being relatively resistant to cisplatin plus TRAIL treatment. The reason behind these discrepancies has yet to be determined. One possibility is that MCF-7 cells lack caspase- 3 expression as a result of a functional deletion mutation in caspase- 3 gene, while expression of caspase-8 and -9 remains normal (30). By contrast, T47D expresses all caspases.

We have previously shown that re-introduction of caspase-3 in MCF-7 cells increases TRAIL-induced apoptosis in PKC- $\delta$-induced anti-estrogen resistance (31). Caspase- 3 mRNA expression levels in breast cancer were shown to be $\geq 10$ - to 50 -fold lower than those in normal breast tissues (24) which is a significant clinical observation. It is possible that Tam/MCF-7 models can be used for more detailed mechanistic studies to identify additional targets that can be used to treat anti-estrogen-resistant breast tumors.

The results from the present investigations suggest that treatment of Tam-resistant cells, i.e., Tam/MCF-7 and Tam/T47D, with cisplatin can enhance TRAIL-induced apoptosis by activating caspases while similar treatment of immortalized CRL8799 normal breast cells had a minimal effect. Individually, platinum compounds, carboplatin or cisplatin and TRAIL have been approved by the FDA to treat different forms of cancer. The results of the present investigation suggest that cisplatin plus TRAIL treatment can be used as a potential and novel treatment strategy for anti-estrogen-resistant breast tumors.

\section{Acknowledgements}

This study is supported by the Department of Pathology at WSU. 


\section{References}

1. Anderson WF, Katki HA and Rosenberg PS: Incidence of breast cancer in the United States: current and future trends. J Natl Cancer Inst 103: 1397-1402, 2011.

2. Marshall E: Breast cancer. Dare to do less. Science 343: $1454-1456,2014$

3. Clarke R, Leonessa F, Welch JN and Skaar TC: Cellular and molecular pharmacology of antiestrogen action and resistance. Pharmacol Rev 53: 25-71, 2001.

4. Lønning PE: Aromatase inhibitors in breast cancer. Endocr Relat Cancer 11: 179-189, 2004

5. Nabha SM, Glaros S, Hong M, Lykkesfeldt AE, Schiff R, Osborne K, et al: Upregulation of PKC-delta contributes to antiestrogen resistance in mammary tumor cells. Oncogene 24: 3166-3176, 2005.

6. Shou J, Massarweh S, Osborne CK, Wakeling AE, Ali S, Weiss H and Schiff R: Mechanisms of tamoxifen resistance: increased estrogen receptor-HER2/neu cross-talk in ER/HER2-positive breast cancer. J Natl Cancer Inst 96: 926-935, 2004.

7. Slamon DJ, Clark GM, Wong SG, Levin WJ, Ullrich A and McGuire WL: Human breast cancer: correlation of relapse and survival with amplification of the HER-2/neu oncogene. Science 235: 177-182, 1987.

8. Kaufmann M, Bajetta E, Dirix LY, Fein LE, Jones SE, Zilembo N, et al: Exemestane is superior to megestrol acetate after tamoxifen failure in postmenopausal women with advanced breast cancer: results of a phase III randomized double-blind trial. The Exemestane Study Group. J Clin Oncol 18: 1399-1411, 2000.

9. Benz CC, Scott GK, Sarup JC, Johnson RM, Tripathy D, Coronado E, et al: Estrogen-dependent, tamoxifen-resistant tumorigenic growth of MCF-7 cells transfected with HER2/neu. Breast Cancer Res Treat 24: 85-95, 1992.

10. Kurokawa H, Lenferink AE, Simpson JF, Pisacane PI, Sliwkowski MX, Forbes JT, et al: Inhibition of HER2/neu (erbB-2) and mitogen-activated protein kinases enhances tamoxifen action against HER2-overexpressing, tamoxifenresistant breast cancer cells. Cancer Res 60: 5887-5894, 2000.

11. Atanaskova N, Keshamouni VG, Krueger JS, Schwartz JA Miller F and Reddy KB: MAP kinase/estrogen receptor crosstalk enhances estrogen-mediated signaling and tumor growth but does not confer tamoxifen resistance. Oncogene 21: 4000-4008, 2002.

12. Ashkenazi A, Pai RC, Fong S, Leung S, Lawrence DA, Marsters SA, et al: Safety and antitumor activity of recombinant soluble Apo2 ligand. J Clin Invest 104: 155-162, 1999.

13. Takeda K, Stagg J, Yagita H, Okumura K and Smyth MJ: Targeting death-inducing receptors in cancer therapy. Oncogene 26: 3745-3457, 2007.

14. Lawrence D, Shahrokh Z, Marsters S, Achilles K, Shih D, Mounho B, et al: Differential hepatocyte toxicity of recombinant Apo2L/TRAIL versions. Nat Med 7: 383-385, 2001.

15. Chinnaiyan AM, Prasad U, Shankar S, Hamstra DA, Shanaiah M, Chenevert TL, et al: Combined effect of tumor necrosis factorrelated apoptosis-inducing ligand and ionizing radiation in breast cancer therapy. Proc Natl Acad Sci USA 97: 1754-1759, 2000.
16. Keane MM, Ettenberg SA, Nau MM, RussellEK and Lipkowitz S: Chemotherapy augments TRAIL-induced apoptosis in breast cell lines. Cancer Res 59: 734-741, 1999.

17. Singh TR, Shankar S, Chen X, Asim M and Srivastava RK: Synergistic interactions of chemotherapeutic drugs and tumor necrosis factor-related apoptosis-inducing ligand/Apo-2 ligand on apoptosis and on regression of breast carcinoma in vivo. Cancer Res 63: 5390-5400, 2003.

18. Kourousis C, Kakolyris S, Androulakis N, Heras P, Vlachonicolis J, Vamvakas L, et al: Salvage chemotherapy with paclitaxel, vinorelbine, and cisplatin (PVC) in anthracyclineresistant advanced breast cancer. Am J Clin Oncol 21: 226-232, 1998.

19. Sledge GW Jr, Loehrer PJ Sr, Roth BJ and Einhorn LH: Cisplatin as first-line therapy for metastatic breast cancer. J Clin Oncol 6: 1811-1814, 1988

20. Lykkesfeldt AE and Briand P: Indirect mechanism of oestradiol stimulation of cell proliferation of human breast cancer cell lines. Br J Cancer 53: 29-35, 1986.

21. Miller RP, Tadagavadi RK, Ramesh G and Reeves WB: Mechanisms of cisplatin nephrotoxicity. Toxins 2: 2490-2518, 2010.

22. Ashkenazi A and Dixit VM: Death receptors: signaling and modulation. Science 281: 1305-1308, 1998.

23. Lin J, Zhang Z, Zeng S, Zhou S, Liu BF, Liu Q, et al: TRAILinduced apoptosis proceeding from caspase-3-dependent and -independent pathways in distinct HeLa cells. Biochem Biophys Res Commun 346: 1136-1141, 2006.

24. Devarajan E, Sahin AA, Chen JS, Krishnamurthy RR, Aggarwal N, Brun AM, et al: Down-regulation of caspase 3 in breast cancer: a possible mechanism for chemoresistance. Oncogene 21: 8843-8851, 2002.

25. Fisher B, Dignam J, Bryant J, DeCillis A, Wickerham DL, Wolmark N, et al: Five versus more than five years of tamoxifen therapy for breast cancer patients with negative lymph nodes and estrogen receptor-positive tumors. J Natl Cancer Inst 88: 1529-1542, 1996.

26. Berstein LM, Zheng H, Yue W, Wang JP, Lykkesfeldt AE, Naftolin F, et al: New approaches to the understanding of tamoxifen action and resistance. Endocr Relat Cancer 10: 267-277, 2003.

27. Horwitz KB: When tamoxifen turns bad. Endocrinology 136: 821-823, 1995

28. Clarke R, Liu MC, Bouker KB, Gu Z, Lee RY, Zhu Y, et al: Antiestrogen resistance in breast cancer and the role of estrogen receptor signaling. Oncogene 22: 7316-7339, 2003.

29. Yde CW, Gyrd-Hansen M, Lykkesfeldt AE, Issinger OG and Stenvang J: Breast cancer cells with acquired antiestrogen resistance are sensitized to cisplatin-induced cell death. Mol Cancer Ther 6: 1869-1876, 2007.

30. Janicke RU, Sprengart ML, Wati MR and Porter AG: Caspase-3 is required for DNA fragmentation and morphological changes associated with apoptosis. J Biol Chem 273: 9357-9360, 1998.

31. Yin S, Sethi S and Reddy KB: Protein kinase C $\delta$ and caspase-3 modulate TRAIL-induced apoptosis in breast tumor cells. J Cell Biochem 111: 979-987, 2010. 